University of Nebraska - Lincoln

DigitalCommons@University of Nebraska - Lincoln

Civil and Environmental Engineering Faculty

Publications

Civil and Environmental Engineering

2011

\title{
Analysis of Existing Work-Zone Sign Supports Using Manual for Assessing Safety Hardware Safety Performance Criteria
}

Jennifer D. Schmidt

University of Nebraska-Lincoln, jennifer.rasmussen@unl.edu

Ronald K. Faller

University of Nebraska - Lincoln, rfaller1@unl.edu

Karla A. Lechtenberg

University of Nebraska - Lincoln, kpolivka2@unl.edu

Dean L. Sicking

University of Nebraska - Lincoln, dsicking1@unl.edu

Follow this and additional works at: https://digitalcommons.unl.edu/civilengfacpub

Part of the Automotive Engineering Commons, and the Transportation Engineering Commons

Schmidt, Jennifer D.; Faller, Ronald K.; Lechtenberg, Karla A.; and Sicking, Dean L., "Analysis of Existing Work-Zone Sign Supports Using Manual for Assessing Safety Hardware Safety Performance Criteria" (2011). Civil and Environmental Engineering Faculty Publications. 129.

https://digitalcommons.unl.edu/civilengfacpub/129

This Article is brought to you for free and open access by the Civil and Environmental Engineering at DigitalCommons@University of Nebraska - Lincoln. It has been accepted for inclusion in Civil and Environmental Engineering Faculty Publications by an authorized administrator of DigitalCommons@University of Nebraska Lincoln. 
Published in Journal of Transportation Safety 3:4 (2011), pp. 237-251.

doi: 10.1080/19439962.2011.599015

Copyright (c) 2011 Taylor \& Francis Group, LLC and The University of Tennessee

Published online December 7, 2011.

\title{
Analysis of Existing Work-Zone Sign Supports Using Manual for Assessing Safety Hardware Safety Performance Criteria
}

\author{
Jennifer D. Schmidt, Ronald K. Faller, \\ Karla A. Lechtenberg, and Dean L. Sicking \\ Midwest Roadside Safety Facility, Nebraska Transportation Center, \\ University of Nebraska-Lincoln Lincoln, Nebraska USA \\ Corresponding author - Ronald K. Faller, Midwest Roadside Safety Facility, Nebraska \\ Transportation Center, University of Nebraska Lincoln, 130 Whittier Building, \\ 2200 Vine St., Lincoln, Nebraska 68583-0853, email rfaller1@unl.edu
}

\begin{abstract}
Over the years, numerous work-zone, portable sign support systems have been successfully crash tested according to the Test Level 3 safety performance guidelines provided in the National Cooperative Highway Research Program Report 350 and accepted for use along our nation's highways. For this study, several crashworthy sign support systems were analyzed to predict their safety performance according to the new evaluation criteria provided in the Manual for Assessing Safety Hardware $(M A S H)$. More specifically, this analysis was conducted to determine which hardware parameters negatively affect a system's safety performance. To verify the accuracy of the analysis, eight systems, four with the 2270P pickup truck and four with the $1100 C$ small car, were evaluated according to the $M A S H$ criteria. Five out of the eight tested systems failed the $M A S H$ criteria, and the other three systems performed in an acceptable manner. As a result of the analysis and verification, several hardware parameters were deemed critical for contributing to system failure under MASH and included sign panel material, top mast height, presence of flags, sign-locking mechanism type, base layout, and system orientation. Flowcharts were developed to assist manufacturers with the design of new sign support systems.
\end{abstract}

Keywords: highway, field research, systems safety, factor analysis, work-zone device, crash test 


\section{Introduction}

The National Cooperative Highway Research Program (NCHRP) Report 350, Recommended Procedures for the Safety Performance Evaluation of Highway Features (Ross, Sicking, Zimmer, \& Michie, 1993), set forth the first guidelines for the safety performance of work-zone traffic control devices. This document recommended that work-zone traffic control devices should be subjected to two full-scale crash tests with a small passenger car. From 1998 through the present, numerous full-scale vehicle crash tests have been conducted at the University of Nebraska-Lincoln on work-zone traffic control devices, such as plastic drums, barricades, portable sign support systems, and rigid-panel sign support systems (Polivka, Rohde, Faller, \& Sicking, 2002). References of all previous testing can be found in Schmidt (2009) and Schmidt, Sicking, Lechtenberg, Faller, and Holloway (2010). Many of these work-zone devices were deemed crashworthy and have been accepted by the Federal Highway Administration (FHWA). If a device showed a propensity to penetrate into the vehicle's occupant compartment, NCHRP Report 350 recommended consideration for an additional crash test to be conducted with a pickup truck. However, because a pickup truck test was not specifically required, this test was never conducted, even when occupant compartment penetration was the primary safety concern.

The American Association of State Highway and Transportation Officials (AASHTO; 2009) published the Manual for Assessing Safety Hardware (MASH), which replaced NCHRP Report 350 as the new safety performance guidelines used for evaluating roadside safety devices. According to $M A S H$, all new work-zone traffic control devices must be crash tested with a small car and a full-size pickup truck. Previously, work-zone sign support systems were specifically developed to meet the NCHRP Report 350 safety performance guidelines utilizing only the $820-\mathrm{kg}$ small car impact condition. Therefore, certain hardware parameters of current crashworthy sign support systems may cause these devices to have an unacceptable safety performance when impacted with larger vehicles. Most of the sign support systems accepted under NCHRP Report 350 were designed to either bridge the windshield and strike the roof or to breakaway and pass over the top of the vehicle without contacting the windshield. However, this behavior was dependent upon an impact with the front-end profile of an 820-kg small car. Vehicles with longer or taller front-end profiles could allow the sign system to contact the windshield and produce an undesirable behavior. Therefore, the devices found in work zones along the National Highway System (NHS) may not be crashworthy for all vehicles larger than the 820-kg small car. As a result, additional research was needed to determine the magnitude of this potential safety problem. 
One of the research objectives for this study was to evaluate the safety performance of selected, crashworthy, sign support systems accepted under NCHRP Report 350 to determine whether these systems would likely meet the MASH safety performance criteria. A further objective of the study was to develop general guidelines for determining which design characteristics produce an increased risk for penetrating the occupant compartment on a wide range of passenger vehicles.

The research effort began with an analytical study of prior full-scale and bogie vehicle crash tests of sign support systems. These crash tests were categorized by their predicted methods of failure under $M A S H$ by comparing observed sign and mast trajectories from tests with small cars to other vehicle geometries. The accuracy of this method was evaluated through fullscale crash testing of selected sign systems that were predicted to have a high propensity for failure. Four full-scale crash tests were performed, two with a small car sedan and two with a pickup truck. Two sign support systems were impacted within each test run, thus resulting in the evaluation of eight systems. The test results were then compared to the predicted behavior. Recommendations were provided to assist manufacturers and highway engineers in designing and implementing safer sign support systems that will accommodate impacts from a broad range of passenger vehicles.

\section{System Analysis}

For this study, it was necessary to predict whether each of the previously crash-tested, sign support systems would perform in an acceptable manner with the $M A S H$ criteria. Therefore, the front-end dimensions were compared for typical test vehicles specified in NCHRP Report 350 and MASH. The $1100 \mathrm{C}$ small car had a longer hood length, a smaller windshield incline, and a shorter windshield length than the $820 \mathrm{C}$ small car. Thus, the impact area of the windshield was set back slightly and was smaller than that configured for the $820 \mathrm{C}$. On the other hand, the $2270 \mathrm{P}$ pickup truck had a smaller windshield incline and longer windshield length than the 2000P pickup truck. Thus, the impact area of the windshield was larger for the 2270P. The hood length was also shorter on the 2270P pickup truck, and the front profile was slightly taller than the 2000 Pickup truck. Using vehicle geometries as well as previous crash test videos and photographs, the research team predicted how each sign support system would perform according to the MASH TL-3 evaluation criteria when impacted by an $1100 \mathrm{C}$ small car and a $2270 \mathrm{P}$ pickup truck at $100 \mathrm{~km} / \mathrm{h}$.

Previously crash-tested, sign support systems were analyzed, including 92 small car full-scale crash tests using the NCHRP Report 350 criteria, 65 small 
car bogie tests, and 18 pickup truck bogie tests (Schmidt, 2009; Schmidt et al., 2010). A ranking from 1 to 4 , as shown in Table 1, was given to each sign support system based on its predicted chance of failing the MASH evaluation criteria. Each system ranking was paired with the failure modes shown in Table 2. The methods of failure were the same for NCHRP Report 350 and $M A S H$; however, most of the evaluation criteria were more objectively defined in $M A S H$.

After failure prediction and crash-test video review, the research team selected 19 hardware parameters that were deemed to contribute to the safety performance of sign support systems. A hardware parameter for a sign support system was described as a mechanism, geometrical measurement, or a particular property associated with a system component. The selected hardware parameters were base layout, base connection type, height to bottom of sign, height to top of mast, height to top of flags, base/sign holder vertical tubing cross-sectional dimension, base/sign holder vertical tubing length, base/sign holder vertical tubing wall thickness, number of mast stages, mast material, mast cross-sectional dimension, mast wall thickness, sign-locking mechanism, sign panel material, aluminum vertical cross-brace length, fiberglass vertical cross-brace thickness, horizontal cross-brace thickness, flag staff material, and system orientation. System orientation was included as a hardware parameter, because it was the only test-related parameter that varied. These 19 hardware parameters were later disaggregated into $142 \mathrm{sub}$ parameters, which were used to categorize similar sign support systems during the analysis. As an example, sub parameters for sign panel material included aluminum, plywood, vinyl, mesh, and plastic.

Table 1. Predicted chance of failing Manual for Assessing Safety Hardware

\begin{tabular}{cl} 
Rank & Probability of Failure \\
\hline 1 & $75-100 \%$ \\
2 & $50-75 \%$ \\
3 & $25-50 \%$ \\
4 & $0-25 \%$ \\
\hline
\end{tabular}

Table 2. Actual and predicted performance methods of failure

Method of Failure

\begin{tabular}{cl} 
Method of Failure & Description \\
\hline 1 & Severe windshield cracking and failure \\
2 & Windshield indention \\
3 & Obstruction of driver visibility \\
4 & Windshield penetration \\
5 & Other occupant compartment penetration \\
6 & Roof deformation \\
7 & Test invalid due to flying debris \\
\hline
\end{tabular}


An analysis was conducted to determine which sub parameter combinations would result in the greatest risk of failure for sign support systems using the MASH guidelines. A total of 175 and 157 systems were analyzed to estimate the safety performance with pickup trucks and small cars, respectively, and included NCHRP Report 350 successes and failures. Only the most critical methods of failure were analyzed and included windshield penetration, other occupant compartment penetration, and roof deformation. Further, only systems that were predicted to fail 50\% to $100 \%$ of the time (Rank 1 or 2) were analyzed.

A methodology was applied to determine the importance of hardware parameters. If a sub parameter corresponded with $50 \%$ or more of predicted system failures for either vehicle type, then its associated hardware parameter was considered to be important. Hardware parameters that were deemed important for both vehicles were sign panel material, height to the top of the mast, mast stages, mast material, flag staff material, and system orientation. For the small car, additional important hardware parameters were height to the top of the flags and sign-locking mechanism. Another important hardware parameter for only the pickup truck was base layout. All other hardware parameters were considered to be unimportant and were discarded from the analysis.

Specific sub parameters that were predicted to cause the most failures with the $M A S H$ pickup truck were a top mast height of 1,905 to $3,353 \mathrm{~mm}$, a two-staged mast, a steel mast, an aluminum sign panel, the use of wooddowel flag staffs or the nonuse of flags, a o-degree system orientation, and an X-footprint base layout. Specific sub parameters that were predicted to cause the most failures with the MASH small car were a top mast height of 1,499 to $2,794 \mathrm{~mm}$, a two-staged mast, a steel mast, an aluminum sign panel, no flags, a o-degree system orientation, and a nut and bolt sign-locking mechanism.

To determine specific systems that had a high rate of failure, systems were analyzed based on the importance of hardware parameters. Separate analyses were conducted for system impacts with the small car and the pickup truck. For each vehicle, systems were sorted by combinations of three of the important hardware parameters. All combinations consisted of subparameters with the highest rates of predicted failure with the MASH criteria. All of the combinations that were determined to be critical are shown in Table 3.

Systems were selected for full-scale crash testing if they were FHWA accepted, matched the parameters shown in Table 3, and were common systems found in the marketplace. The final test matrix was configured after considering input by the FHWA. Due to limitations on the different types of sign support systems previously tested at the Midwest Roadside Safety Facility (MwRSF), the FHWA recommended sign support systems that 
Table 3. Recommended test matrix-Sign support systems

\begin{tabular}{|c|c|}
\hline Pickup Truck Recommendations & Small Car Recommendations \\
\hline $\begin{array}{l}\text { X-footprint, double vertical spring, top of } \\
\text { mast 2,286 mm, bottom of sign } 457 \mathrm{~mm} \text {, } \\
\text { flags, vinyl or aluminum panel, } 0 \circ \text { or } 90^{\circ}\end{array}$ & $\begin{array}{l}\text { X-footprint, double vertical spring, top of } \\
\text { mast 2,388 mm, bottom of sign } 457 \mathrm{~mm} \text {, } \\
\text { flags, aluminum or vinyl panel, } 0 \text {. }\end{array}$ \\
\hline $\begin{array}{l}\text { Parallel dual upright, top of mast 2,184 } \\
\text { mm, bottom of sign } 381-610 \mathrm{~mm} \text {, no } \\
\text { flags, aluminum panel, } 0 \circ\end{array}$ & $\begin{array}{l}\text { Parallel dual upright, top of mast } \\
2,134-2,743 \mathrm{~mm} \text {, bottom of sign } 381-610 \\
\mathrm{~mm} \text {, no flags, aluminum panel, } 0 \circ \text { or } 90 \circ\end{array}$ \\
\hline $\begin{array}{l}\text { X-footprint, torsion spring, top of mast } \\
\text { 2,286 mm, bottom of sign } 305-457 \mathrm{~mm} \text {, } \\
\text { flags, aluminum or vinyl panel, } 0 \text { ॰ }\end{array}$ & $\begin{array}{l}\text { X-footprint, torsion spring, top of mast } \\
2,286 \mathrm{~mm} \text {, bottom of sign } 305-381 \mathrm{~mm} \text {, } \\
\text { flags, vinyl panel, } 0 \text { or or } 90^{\circ}\end{array}$ \\
\hline $\begin{array}{l}\text { X-footprint, double vertical spring, top of } \\
\text { mast 3,302 mm, bottom of sign } \\
\text { 1,524 mm, flags, aluminum panel, } 90 \text { 。 }\end{array}$ & $\begin{array}{l}\text { X-footprint, rigid base, no mast, bottom of } \\
\text { sign } 457 \mathrm{~mm} \text {, flags, vinyl panel with } \\
\text { aluminum cross-bracing, } 0 \text { 。 }\end{array}$ \\
\hline $\begin{array}{l}\text { Parallel dual upright, top of mast } \\
3,302 \mathrm{~mm} \text {, bottom of sign } 1,524 \mathrm{~mm} \text {, no } \\
\text { flags, aluminum panel, } 90 \text { 。 }\end{array}$ & $\begin{array}{l}\text { Parallel dual upright, top of mast } \\
1,524-2,108 \mathrm{~mm} \text {, bottom of sign } 457- \\
914 \mathrm{~mm} \text {, no flags, aluminum panel, 0。 }\end{array}$ \\
\hline $\begin{array}{l}\text { X-footprint, slipbase, top of mast } \\
3,302 \mathrm{~mm} \text {, bottom of sign } 1,524 \mathrm{~mm} \text {, } \\
\text { flags, aluminum panel, } 0 \circ \text { or } 90 \text { 。 }\end{array}$ & \\
\hline
\end{tabular}

Source: Schmidt (2009).

incorporated specific important hardware parameters and those that were believed to be critical for failure with either the small car or pickup truck vehicles. Further details on this project have been omitted but are described in the noted references (Schmidt, 2009; Schmidt et al., 2010).

\section{Work-Zone Sign Support Systems}

A total of eight work-zone traffic control devices were crash tested under this study, as shown in Table 4 and Figure 1. These crash tests were conducted on prior FHWA-accepted, NCHRP Report 350-crashworthy, workzone sign support systems.

For each test, two sign support systems were impacted with one vehicle. The two systems were longitudinally placed approximately $18 \mathrm{~m}$ apart and offset to impact the left- and right-front quarter points of the vehicle. MwRSF researchers, in consultation with FHWA personnel, chose to not deliberately divulge the system names or manufacturers of the proprietary devices to reduce the propensity for the unapproved use of unsatisfactory test results. 
Table 4. Final test matrix-sign support systems

\begin{tabular}{|c|c|c|}
\hline Test No. & System No. & System Description \\
\hline WZ09-1 & $1 \mathrm{~A}$ & $\begin{array}{l}\text { Double-upright coil, spring-mounted sign support, } \\
\text { aluminum sign panel, 90-degree impact with } 2270 \mathrm{P}\end{array}$ \\
\hline WZ09-1 & $1 \mathrm{~B}$ & $\begin{array}{l}\text { Parallel dual upright sign support, aluminum sign } \\
\text { panel, amber warning light, sandbag on each leg, } \\
\text { 90-degree impact with } 2270 \mathrm{P}\end{array}$ \\
\hline WZ09-2 & $2 \mathrm{~A}$ & $\begin{array}{l}\text { Double-upright coil, spring-mounted sign support, } \\
\text { aluminum sign panel, 0-degree impact with } 1100 \mathrm{C}\end{array}$ \\
\hline WZ09-2 & $2 B$ & $\begin{array}{l}\text { Tripod-mounted sign support, aluminum sign panel, } \\
\text { 90-degree impact with } 1100 \mathrm{C}\end{array}$ \\
\hline WZ09-3 & $3 \mathrm{~A}$ & $\begin{array}{l}\text { Double-upright coil, spring-mounted sign support, } \\
\text { roll-up sign panel, } 0 \text {-degree impact with } 2270 \mathrm{P}\end{array}$ \\
\hline WZ09-3 & $3 B$ & $\begin{array}{l}\text { Double-upright coil, spring-mounted sign support, } \\
\text { aluminum sign panel, } 90 \text {-degree impact with } 2270 \mathrm{P}\end{array}$ \\
\hline WZ09-4 & $4 \mathrm{~A}$ & $\begin{array}{l}\text { Double-upright coil, spring-mounted sign support, } \\
\text { aluminum sign panel, 0-degree impact with } 1100 \mathrm{C}\end{array}$ \\
\hline WZ09-4 & $4 B$ & $\begin{array}{l}\text { Dual extension, spring-mounted sign support, roll-up } \\
\text { sign panel, 90-degree impact with } 1100 \mathrm{C}\end{array}$ \\
\hline
\end{tabular}

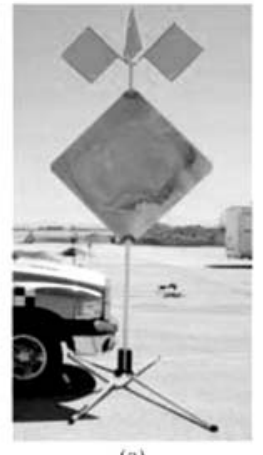

(a)

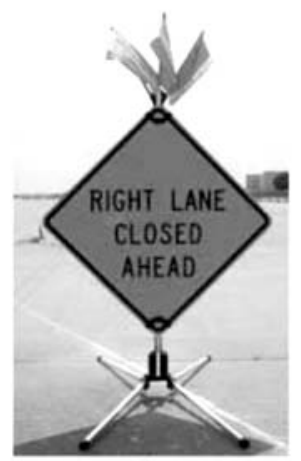

(c)

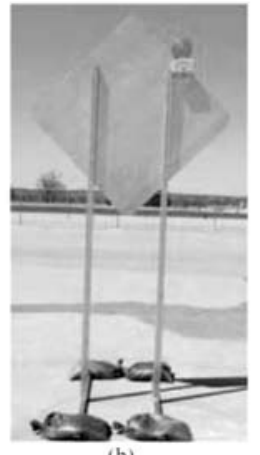

(b)

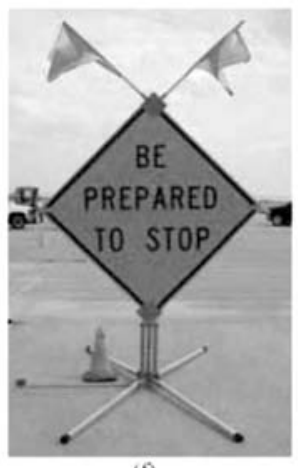

(f)

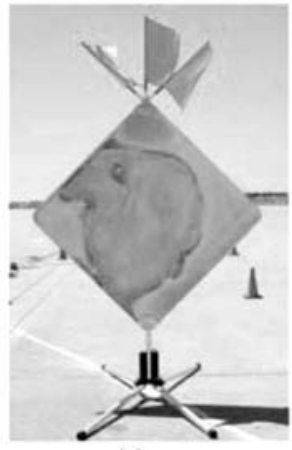

(c)

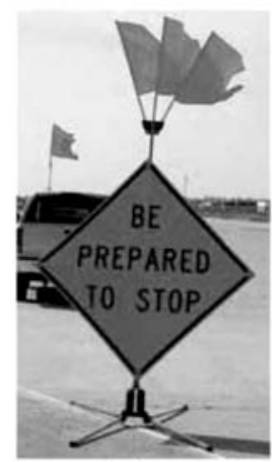

(g)

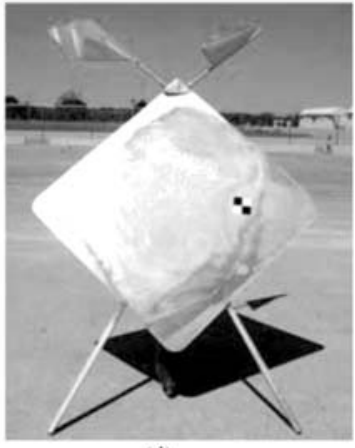

(d)

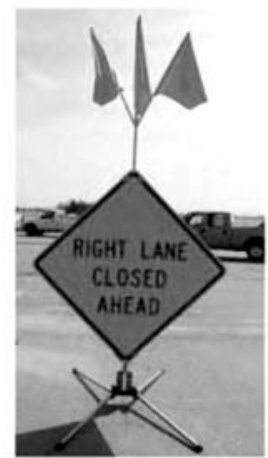

Figure 1. Work-zone sign support systems: (a) System 1A, (b) System 1B, (c) System 2A, (d) System 2B, (e) System 3A, (f) System 3B, (g) System 4A, and (h) System 4B. 


\section{Evaluation Criteria}

All newly developed work-zone traffic control devices, such as portable sign support systems, must satisfy impact safety standards provided in MASH (AASHTO, 2009) to be accepted by the FHWA for use along the NHS. According to FHWA's Submission Guidelines attached to the July 1997 memorandum, Action: Identifying Acceptable Highway Safety Features (FHWA, 1997), work-zone traffic control devices fall into Category 2. Devices in this hardware category are not expected to produce a significant change in vehicular velocity. However, these devices may still pose safety risks to motorists because they have the potential to penetrate a windshield, injure a worker, or cause vehicle instability when driven over or lodged under a vehicle.

According to TL-3 of MASH, work-zone traffic control devices must be subjected to three full-scale vehicle crash tests. The three full-scale crash tests are as follows:

1. Test designation no. 3-70 consisting of a 1,100-kg small car, designated $1100 \mathrm{C}$, impacting at a nominal speed of 30 $\mathrm{km} / \mathrm{h}$ and at a critical impact angle (CIA).

2. Test designation no. 3-71 consisting of a 1,100-kg small car, designated 1100C, impacting at a speed of $100 \mathrm{~km} / \mathrm{h}$ and at a CIA.

3. Test designation no. 3-72 consisting of a 2,270-kg pickup truck, designated $2270 \mathrm{P}$, impacting at a speed of $100 \mathrm{~km} / \mathrm{h}$ and at a CIA.

The low-speed test is intended to evaluate the breakaway, fracture, or yielding mechanism of the device. The high-speed test is intended to evaluate vehicular stability, test article trajectory, and occupant risk factors. Because most work-zone traffic control devices have a relatively small mass (less than $100 \mathrm{~kg}$ ), the high-speed crash test is more critical due to the propensity of the test article to penetrate into the occupant compartment. Therefore, test designation no. 3-70 was deemed unnecessary for this project. In addition, testing should be conducted at the critical impact angle, which is the worst-case impact condition in which the traffic control device will be deployed along the roadway. For safety devices that can be used near an intersection 
and can be impacted from virtually any direction, testing is recommended at 90 degrees from normal and at the most critical orientation between 0 and 25 degrees.

Evaluation criteria for full-scale vehicle crash testing are based on three appraisal areas: (1) structural adequacy, (2) occupant risk, and (3) vehicle trajectory after collision. Criteria for structural adequacy are intended to evaluate the ability of the work-zone traffic control device to break away, fracture, or yield in a predictable manner. Occupant risk evaluates the degree of hazard to occupants in the impacting vehicle, including windshield damage. Vehicle trajectory after collision is a measure of the potential for the postimpact trajectory of the vehicle to cause subsequent multivehicle accidents, thereby subjecting occupants of other vehicles to undue hazards or to subject the occupants of the impacting vehicle to secondary collisions with other vehicles and/or fixed objects. The full-scale vehicle crash tests were conducted and reported in accordance with the procedures provided in $M A S H$ for Category 2 devices.

Windshield damage is a major area of concern when evaluating the safety performance of a work-zone traffic control device (FHWA, 2009). The windshield should not be shattered nor damaged in such a way that visibility is significantly obstructed. Minor chipping and cracking of the windshield is acceptable. Indentation of the windshield by greater than $76 \mathrm{~mm}$, a tear in the plastic liner or penetration of the test article through the windshield is not permitted. Also, roof deformation greater than $102 \mathrm{~mm}$ and any other occupant compartment penetration are not permitted.

\section{Full-Scale Crash Tests}

\subsection{Test No. WZog-1}

The 2,340-kg pickup truck with a simulated occupant seated in the rightfront seat impacted system no. 1A, a double-coil, spring-mounted sign support with an aluminum sign panel, oriented end-on to the vehicle, at a speed of $102.1 \mathrm{~km} / \mathrm{h}$ and at an angle of 90 degrees. During test no. WZo9-1A, the mast fractured away from the base and the sign panel disengaged from the lower rigid bracket and penetrated the windshield with a maximum indentation of $330 \mathrm{~mm}$. In addition, the flags disengaged and the flag holder penetrated the roof and caused $95 \mathrm{~mm}$ of roof crush, as shown in Figure 2. The 


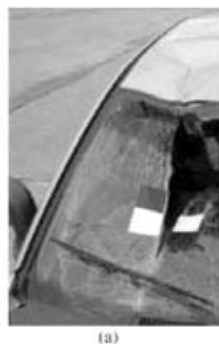

(a)

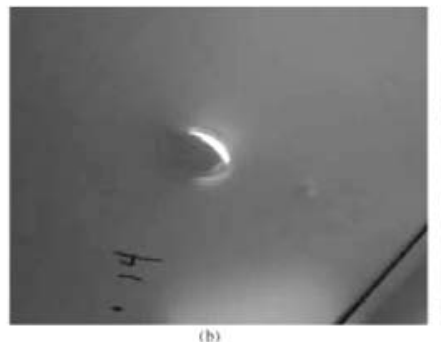

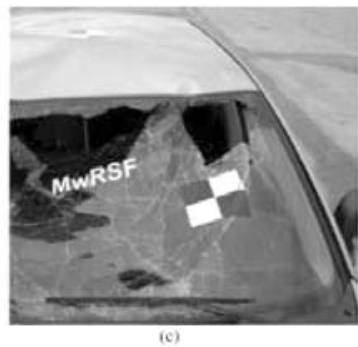

Figure 2. Vehicle damage, test no. WZog-1: (a) System 1A windshield, (b) System 1A roof, and (c) System 1B windshield.

performance of system no. $1 \mathrm{~A}$ was determined to be unacceptable according to the MASH criteria due to roof and windshield penetration, windshield indentation greater than $76 \mathrm{~mm}$, and significant windshield cracking. Occupant impact velocity (OIV) and occupant ride down acceleration (ORA) were not calculated due to the small change in velocity.

The pickup truck then impacted system no. 1B, a parallel dual upright sign support with an aluminum sign panel and amber warning light, oriented end-on to the vehicle at a speed of $99.8 \mathrm{~km} / \mathrm{h}$ and at an angle of 90 degrees. During test no. WZo9-1B, both masts fractured and the sign support rotated onto the hood. Subsequently, the sign panel and attached warning light rotated into the windshield, penetrated the windshield, and caused $229 \mathrm{~mm}$ of windshield indentation, as shown in Figure 2. The performance of system no. $1 \mathrm{~B}$ was determined to be unacceptable according to the $M A S H$ criteria due to windshield penetration, windshield indentation greater than $76 \mathrm{~mm}$, and significant windshield cracking. OIV and ORA were not calculated due to the small change in velocity.

\subsection{Test No. WZog-2}

The 1,167-kg small car with a simulated occupant seated in the right-front seat impacted system no. 2A, a double-upright coil, spring-mounted sign support with an aluminum sign panel, oriented head-on to the vehicle, at a speed of $103.2 \mathrm{~km} / \mathrm{h}$ and at an angle of o degrees. During test no. WZo9-2A, the mast fractured and the sign panel disengaged into the windshield and caused $57 \mathrm{~mm}$ of windshield indentation, as shown in Figure 3. The performance of system no. 2A was determined to be successful according to the $M A S H$ criteria, because the maximum deformation of $57 \mathrm{~mm}$ was below the $76 \mathrm{~mm}$ maximum value defined in $M A S H$. OIV and ORA were not calculated due to the small change in velocity.

The small car then impacted system no. 2B, a tripod-mounted sign support with an aluminum sign panel, oriented end-on to the vehicle at a speed 

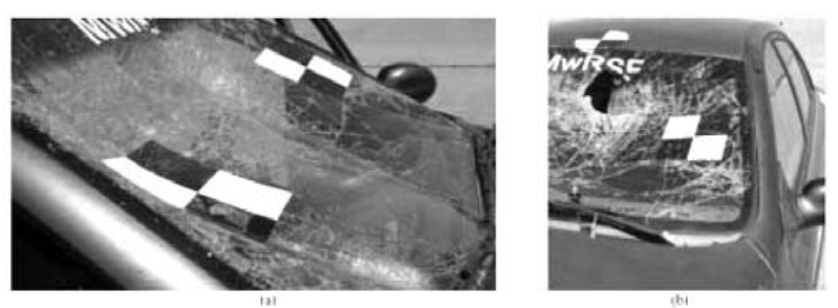

Figure 3. Vehicle damage, test no. WZog-2: (a) System 2A, and (b) System 2B.

of $98.8 \mathrm{~km} / \mathrm{h}$ and at an angle of 90 degrees. During test no. WZo9-2B, the sign stand rotated onto the hood and the flag holder and mast penetrated the windshield with a maximum indentation of $197 \mathrm{~mm}$ and $19 \mathrm{~mm}$ of roof crush, as shown in Figure 3. In addition, the flags fractured inside the car. The performance of system no. 2B was determined to be unacceptable according to the MASH criteria due to significant windshield cracking, windshield indentation greater than $76 \mathrm{~mm}$, and windshield penetration. The mast impacted the top of the windshield which was already weakened from the impact with system no. $2 \mathrm{~A}$, but the penetration was significant and was believed to have occurred without the prior damage. OIV and ORA were not calculated due to the small change in velocity.

\subsection{Test No. WZog-3}

The 1,168-kg small car with a simulated occupant seated in the right-front seat impacted system no. 3A, a double-upright coil, spring-mounted sign support with a vinyl roll-up sign panel oriented head-on to the vehicle, at a speed of $106.1 \mathrm{~km} / \mathrm{h}$ and at an angle of o degrees. During test no. WZog$3 \mathrm{~A}$, the mast fractured and the sign panel disengaged into the windshield and caused $102 \mathrm{~mm}$ of windshield indentation, as shown in Figure 4. The performance of system no. 3A was determined to be unacceptable according to the $M A S H$ criteria due to significant windshield cracking and windshield indentation greater than $76 \mathrm{~mm}$. OIV and ORA were well below the recommended limits.
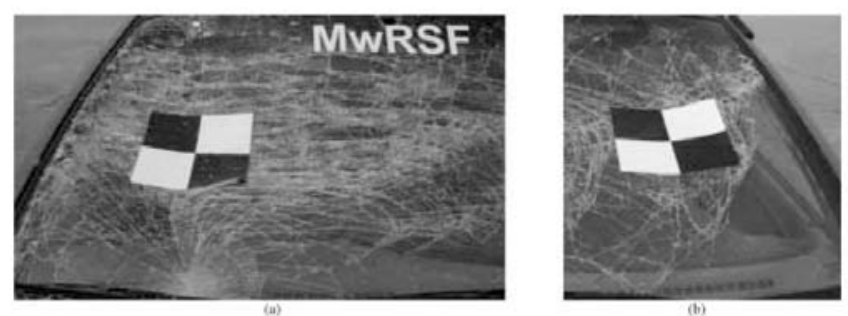

Figure 4. Vehicle damage, test no. WZog-3: (a) System 3A, and (b) System 3B. 
The small car then impacted system no. 3B, a double-upright coil, springmounted sign support with an aluminum sign panel oriented end-on to the vehicle at a speed of $100.9 \mathrm{~km} / \mathrm{h}$ and at an angle of 90 degrees. During test no. WZo9-3B, the upper and lower masts separated and the horizontal crossbrace impacted the windshield and caused $57 \mathrm{~mm}$ of windshield indentation, as shown in Figure 4. The performance of system no. 3B was determined to be acceptable according to the MASH criteria because the maximum deformation of the windshield was only $57 \mathrm{~mm}$, which is below the $76 \mathrm{~mm}$ maximum value defined in $M A S H$. Windshield cracking was insufficient to cause obstruction of visibility, and the horizontal fiberglass cross-brace did not appear to have the potential for windshield penetration. OIV and ORA were well below the recommended limits.

\subsection{Test No. WZog-4}

The 2,339-kg pickup truck with a simulated occupant seated in the right-front seat impacted system no. 4A, a double-upright coil, spring-mounted sign support with an aluminum sign panel oriented head-on to the vehicle, at a speed of $105.9 \mathrm{~km} / \mathrm{h}$ and at an angle of o degrees. During test no. WZo9-4A, the connection between the lower and upper masts failed, the sign panel impacted the hood, and the flag holder penetrated the windshield and caused $10 \mathrm{~mm}$ of windshield indentation. In addition, one of the front legs penetrated the floorboard behind the driver's seat, as shown in Figure 5. The performance of system no. 4A was determined to be unacceptable according to the MASH criteria due to windshield and floorboard penetration and post impact vehicle trajectory. It should be noted that one of the legs on system no. 4A wedged behind the right-front tire that inhibited the braking system on the pickup truck. This caused the pickup truck to veer to the right and impact a concrete barrier prior to stopping. This result could be considered a danger to workers in the work-zone area as well as to the occupants of vehicle depending on what objects would have been located on the right side of the roadway. OIV and ORA were not calculated due to the small change in velocity.

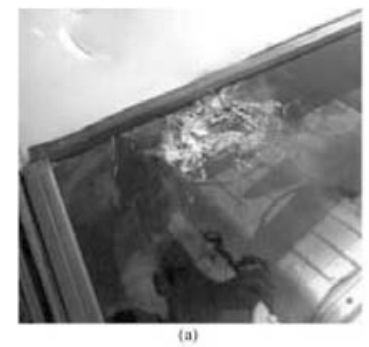

(a)
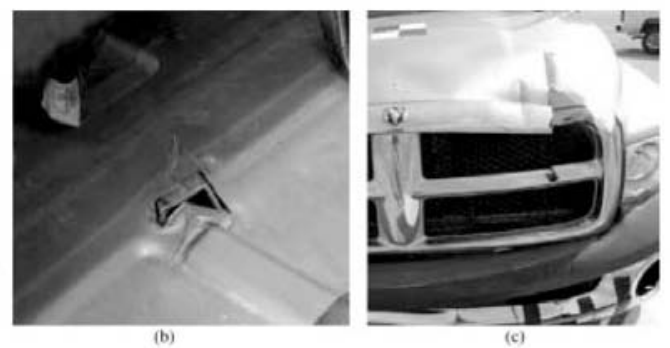

Figure 5. Vehicle damage, test no. WZo9-4: (a) System 4A windshield, (b) System 4A floorboard, and (c) System 4B hood. 
The pickup truck then impacted system no. 4B, a dual-extension, springmounted sign support with a vinyl roll-up sign panel oriented end-on to the vehicle at a speed of $103.7 \mathrm{~km} / \mathrm{h}$ and at an angle of 90 degrees. During test no. WZo9-4B, the sign panel impacted the hood and disengaged from the rigid brackets, the connection between the lower and upper masts failed, and the system rotated over the truck without further contact, as shown in Figure 5. System no. 4B was determined to be acceptable according to the $M A S H$ criteria because the components of system no. $4 \mathrm{~B}$ did not contact the pickup truck's windshield or roof. OIV and ORA were not calculated due to the small change in velocity.

\section{Discussion}

Following the crash testing program, the hardware parameters that were predicted to be important for failure were reevaluated to determine their actual contribution to system performance. The following hardware parameters are discussed in this section: aluminum sign panels, height to top of mast, two-staged masts, mast materials, presence of flags, X-footprint base layout, and rigid bracket sign-locking mechanism.

Aluminum sign panels were shown to be important for the pickup truck and small car. Four of the six aluminum-panel systems failed. When oriented at 90 degrees, the sharp corners on the rigid panels penetrated the windshield and deformed the roof (system no. 1A). The aluminum sign panels flexed and disengaged upon impact when oriented at o degrees, which caused excessive windshield deformation and cracking (system no. 3a).

Not only is the sign panel material important, the reflective sheeting on the face of the aluminum may decrease the safety performance of a system. System nos. 2A and 3A were nearly identical sign support systems, except that system no. 2A had a blank aluminum sign panel, and system no. 3A had an aluminum sign panel with reflective sheeting. The system with reflective sheeting caused $102 \mathrm{~mm}$ of windshield deformation and remained intact with the windshield after the impact, whereas the system without reflective sheeting only caused $57 \mathrm{~mm}$ of indentation and the panel slid over the windshield and roof of the vehicle. The friction between the reflective sheeting and the windshield may have contributed to the additional deformation.

The critical range for the height to the top of the mast was predicted to be 1,905 to $3,353 \mathrm{~mm}$ for the pickup truck. Three of the four systems were in this critical range, and two of the three failed the $M A S H$ criteria. System no. 1A was $84 \mathrm{~mm}$ above the critical range and failed the $M A S H$ criteria with significant windshield penetration, so it is evident that the range should be extended with an upward bound of at least 3,437 $\mathrm{mm}$. 
All sign support systems that were crash tested with small cars were in the critical range for the height to the top of the mast, which was predicted to be 1,499 to $2,794 \mathrm{~mm}$. For sign systems at the lower part of the range, the mast penetrated the windshield (system no. 2B). For sign systems at the upper part of the range, the sign panel caused excessive windshield deformation and cracking (system no. 3B).

All systems, except for system no. 2B, were classified as having two-stage masts, which was predicted to be critical for the small car and pickup truck. Four of the seven systems with two-stage masts failed the MASH criteria. Most common sign systems were designed with two-stage masts for easier storage and portability, and the number of stages was not dependent on the height of the system. Because the height of the mast has shown to be very important factor on the performance of sign systems, the number of mast stages was determined to be insignificant.

Steel mast material was predicted to be important for the pickup truck and the small car. Three of the five systems tested with steel masts failed the MASH criteria. However, two of the three systems that were tested with aluminum masts also failed the $M A S H$ criteria. In general, most masts with a low-breakaway point in work-zone devices tend to be made out of aluminum, whereas most non-breakaway masts or masts with a high-breakaway point tend to be made out of steel. System nos. 1B and 2B deformed around the hood of the vehicles and did not breakaway and then later penetrated the windshields. System no. 4B had a high-breakaway point, which allowed the base to get caught in the undercarriage of the pickup truck and penetrate the floorboard. System nos. 1A and 3A had low-breakaway points that fractured almost immediately upon impact, and the sign panels rotated into the vehicles' windshields. So, it is more likely that the breakaway mechanism or lack thereof is contributing to sign support system failure with the $M A S H$ criteria, rather than the mast material.

The addition of the flags was inconclusive. Flags were present in seven of the eight systems. The flags in system no. $2 \mathrm{~B}$ were the only flags that created a potential hazard when the flag staffs fractured inside the occupant compartment. The flag holder, which was left exposed in system nos. $1 \mathrm{~A}$ and $4 \mathrm{~A}$ when the flags disengaged or fractured, caused roof penetration and windshield penetration, respectively. Although the flag staff material and height to top of the flags was found to be important in the analysis, the presence or lack of flags was found to be more important during the crash tests. More importantly, the presence of a flag holder with no flags (or broken flag staffs) seemed to be the most critical situation, because the exposed metal ends have the potential to penetrate the windshield or roof. Each system should be tested and used in the field in the same conditions, either with a flag holder and flags installed, or with no flag holder.

Three of the four systems tested with the pickup truck had X-footprint base layouts, which were predicted to be critical. System no. 4A was oriented 
at o degrees, and one of the legs penetrated the floorboard of the pickup truck. The legs of X-footprint bases are often intended to fold up for easy portability. However, the legs tend to release from their locked positions during vehicular impacts, thus allowing them to fold up into the undercarriage. This phenomenon did not occur when the system was oriented at 90 degrees nor with the small car.

The rigid bracket sign-locking mechanism was found to affect the performance of systems tested with the small car. In system no. 3A, the rigid brackets disengaged the sign panel and caused the sign panel to indent the windshield. The rigid bracket with the flag holder on system no. 2B caused significant windshield penetration. The sign locking mechanism may be a contributor to failure of portable sign supports, but it is also dependent on the original design of the locking mechanism. Rigid brackets that were designed to disengage the aluminum panel may produce an unsafe performance if the panel impacts the windshield. However, rigid brackets that were designed to keep the aluminum panel intact may still allow the mast or sign panel to impact the windshield. The rigid bracket sign-locking mechanism that produces the safest performance should be analyzed for individual systems.

System orientation was not an important hardware parameter independently, because the performance of a system in either orientation is dependent on the combination of other hardware parameters. Three of the five systems that were tested at the 90-degree orientation (system nos. 1A, 1B, and $2 \mathrm{~B}$ ) failed the $M A S H$ criteria by windshield penetration. Two of the three systems that were tested at the o-degree orientation failed the MASH criteria by excessive windshield deformation (system no. $3 \mathrm{~A}$ ) or windshield and floorboard penetration (system no. 4A). The most critical orientation for a system can be determined by evaluating all the hardware parameters on a given system.

\section{Conclusions}

A total of eight crash tests were conducted on various sign support systems that were predicted to fail the $M A S H$ criteria. Three of the work-zone traffic control devices satisfactorily met the safety performance evaluation criteria for one of the two required TL-3 crash tests set forth in MASH. These devices include:

1. A double-upright coil, spring-mounted, sign support with an aluminum sign panel mounted at a height of $511 \mathrm{~mm}$ from the ground to the bottom of the sign panel impacted at a o-degree orientation (System no. 2A - Test designation no. 3-71). 
2. A dual-extension, spring-mounted, sign support with a vinyl rollup sign panel mounted at a height of $533 \mathrm{~mm}$ from the ground to the bottom of the sign panel impacted at a 9o-degree orientation (System no. 3B - Test designation no. 3-71).

3. A double-upright coil, spring-mounted, sign support with an aluminum sign panel mounted at a height of $379 \mathrm{~mm}$ from the ground to the bottom of the sign panel impacted at a 90-degree orientation (System no. 4B - test designation no. 3-72).

Five work-zone traffic control devices performed unsatisfactorily according to the $M A S H$ evaluation criteria even though prior acceptable performance was obtained according to NCHRP Report No. 350. These devices include:

1. A double-upright coil, spring-mounted, sign support with an aluminum sign panel mounted at a height of $1,522 \mathrm{~mm}$ from the ground to the bottom of the sign panel impacted at a 90-degree orientation (System no. 1A - Test designation no. 3-72).

2. A parallel dual upright sign support with an aluminum sign panel mounted at a height of $1,565 \mathrm{~mm}$ from the ground to the bottom of the sign panel impacted at a 90-degree orientation (System no. 1B - Test designation no. 3-72).

3. A tripod-mounted, sign support with an aluminum sign panel mounted at a height of $373 \mathrm{~mm}$ from the ground to the bottom of the sign panel impacted at 9o-degree orientation (System no. 2B - Test designation no. 3-71).

4. A double-upright coil, spring-mounted, sign support with an aluminum sign panel mounted at a height of $457 \mathrm{~mm}$ from the ground to the bottom of the sign panel impacted at a o-degree orientation (System no. 3A - Test designation no. 3-71).

5. A double-upright coil, spring-mounted, sign support with a vinyl roll-up sign panel mounted at a height of $340 \mathrm{~mm}$ from the ground to the bottom of the sign panel impacted at a o-degree orientation (System no. 4A - Test designation no. 3-72).

The safety performance of sign support systems is a function of many hardware parameters, such as the stiffness and strength of the mast and stand, height of sign panel and mast, sign panel material, and flag and light attachments. Consequently, slight differences in system details can potentially lead to very different results. Extreme care should be taken when attempting to categorize similar products from various manufacturers. Fullscale crash testing is the only way to verify the safety performance of a particular device. 
The research conducted and described herein was not comprehensive of all work-zone traffic control devices. Therefore, the results cannot be used to predict acceptance nor failure of a particular work-zone traffic control device. The methodology utilized for categorizing and sorting the work-zone systems was specifically tailored for use in the crash testing program for this project. It should be noted that there are other existing sign support systems that were not analyzed within this study that would also have the potential to fail the MASH evaluation criteria.

The breakaway mechanism (or lack thereof) is a key component of sign support systems that affects where and how the mast and/or sign panel will strike the vehicle. This feature was not considered as an independent hardware parameter within this study, because breakaway sign support systems do not always behave as they were intended to, and some sign systems do not result in mast fracture or sign panel release upon impact. Therefore, it was difficult to classify sign support systems as breakaway or non-breakaway when they may not perform as originally intended. In general, the breakaway mechanism (or lack thereof) needs to be analyzed on individual systems in conjunction with other hardware parameters to determine if it is beneficial or detrimental to the safety performance of the system.

\section{Recommendations}

All of the crash-tested systems had previously passed the TL-3 small car criteria defined in NCHRP Report 350. Therefore, it was expected that the systems tested in this study using the MASH small car could also perform satisfactorily, because there were only slight changes in vehicle geometries. Unfortunately, two out of the four systems tested with the $1100 \mathrm{C}$ small car vehicle failed the MASH criteria. Thus, it is recommended that existing systems with a marginal pass under NCHRP Report 350, those similar to the two systems that failed the $M A S H$ criteria or those systems exhibiting any of the small car hardware parameters shown in Table 5 should be tested under MASH using test designation no. 3-71 to verify their safety performance.

Table 5. Hardware parameters believed to be important for failure

\begin{tabular}{lll} 
Hardware Parameter & Pickup Truck & Small Car \\
\hline Sign panel material & Aluminum & Aluminum \\
Height to top of mast & $1,905-3,429 \mathrm{~mm}$ & $1,499-2,794 \mathrm{~mm}$ \\
Presence of flags & W/o Flags & W/ and w/o Flags \\
Orientation & 0 and 90 degrees & 0 and 90 degrees \\
Sign-locking mechanism & NA & Rigid brackets \\
Base layout & X-footprint & NA \\
\hline
\end{tabular}

Source: Schmidt (2009). 


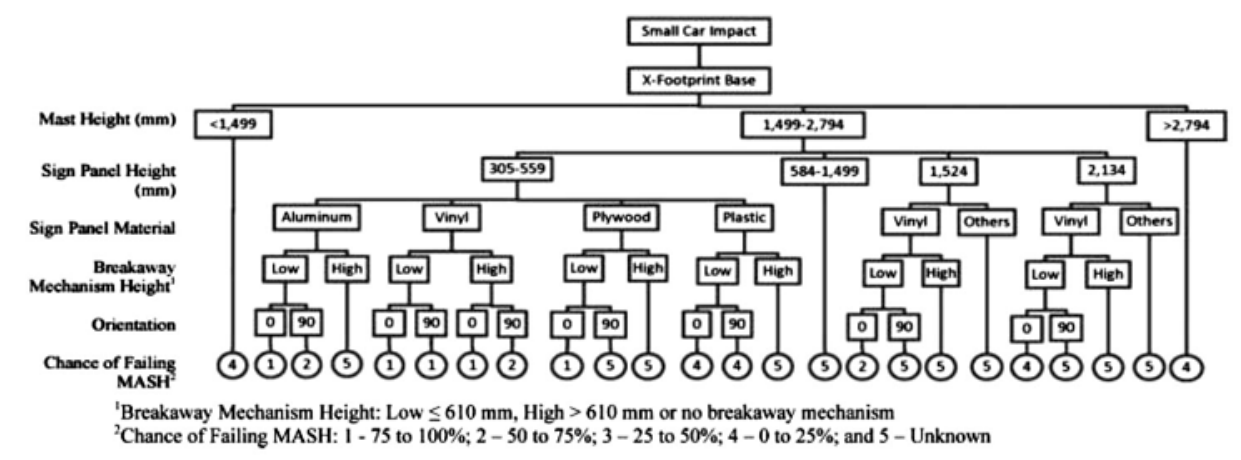

Figure 6. TL-3 Manual for Assessing Safety Hardware impact prediction with small car -Xfootprint base. Source: Schmidt (2009).

No sign support systems have been full-scale crash tested with a pickup truck prior to this study. Thus, it is recommended that existing systems that are similar to those tested herein or designs exhibiting any of the pickup truck hardware parameters shown in Table 5 be tested under MASH using test designation no. 3-72 to verify their safety performance.

Sign support systems with rigid panels should be crash tested using the same configuration that will be used in the field. As such, the sign blanks shall be covered with the actual reflective sheeting when used in crash testing programs to obtain the most accurate results.

The results from this research study demonstrated that sign support systems that were successfully crash tested under NCHRP Report 350 may not necessarily meet the $M A S H$ impact safety standards. All new sign support systems are required to be subjected to full-scale crash testing with small car and pickup truck vehicles when using the MASH safety performance guidelines. Manufacturers are cautioned when designing new systems with the hardware parameters shown in Table 5 , as the inclusion of these parameters have shown an increased risk for system hardware to penetrate the occupant compartment. The use of these hardware parameters has demonstrated the potential for systems to fail the $M A S H$ criteria, especially when those parameters were used in conjunction with one another. Specific combinations of parameters that have been evaluated with the MASH criteria have been presented in flowcharts, such as the flowchart shown in Figure 6, and are provided in the noted references (Schmidt, 2009; Schmidt et al., 2010).

Acknowledgments - The authors wish to acknowledge several sources that contributed to this project, including the Mid-America Transportation Center at the University of NebraskaLincoln, the Smart Work Zone Deployment Initiative at the Center for Transportation Research Education at Iowa State University, Dicke Safety Products, and Nicholas Artimovich and Matt Lupes from the U.S. Department of Transportation Office of Safety Design. 


\section{References}

American Association of State Highway and Transportation Officials. (2009). Manual for assessing safety hardware (MASH). Washington, DC: American Association of State Highway and Transportation Officials.

Federal Highway Administration. (1997). Memorandum on action: Identifying acceptable highway safety features, File Designation HNG-14. Washington, DC: Federal Highway Administration.

Federal Highway Administration. (2005). Windshield damage for Category II work zone traffic control devices guidance for pass/fail. Retrieved from http:// safety.fhwa.dot.gov/roadway dept/policy guide/road hardware/memo1105/ attach3a.cfm

Polivka, K. A., Rohde, J. R., Faller, R. K., \& Sicking, D. L. (2002). Crash testing and analysis of work zone sign supports. Transportation Research Record, 1797, 44-52.

Ross, H. E., Sicking, D. L., Zimmer, R. A., \& Michie, J. D. (1993). Recommended procedures for the safety performance evaluation of highway features (National Cooperative Highway Research Program Report 350), Washington, DC: Transportation Research Board.

Schmidt, J. D. (2009). Analysis of existing work-zone devices with MASH safety performance criteria (Unpublished master's thesis). University of Nebraska-Lincoln.

Schmidt, J. D., Sicking, D. L., Lechtenberg, K. A., Faller, R. K., \& Holloway, J. C. (2010). Analysis of existing work-zone devices with MASH safety performance criteria, (Transportation Research Report No. TRP-03-225-10). Lincoln, NE: University of Nebraska-Lincoln, Midwest Roadside Safety Facility. 